\title{
Poder e compartilhamento da informação: relações e implicações na arena política organizacional
}

\author{
Rita de Cássia Martins de Oliveira Ventura \\ Doutoranda; Universidade Federal de Minas Gerais (UFMG), Belo Horizonte, MG, Brasil; \\ ritakmartins@hotmail.com \\ Mônica Erichsen Nassif \\ Doutora; Universidade Federal de Minas Gerais (UFMG), Belo Horizonte, MG, Brasil; \\ mnassif@eci.ufmg.br
}

\begin{abstract}
Resumo: Discussões sobre a importância do compartilhamento da informação e de ações para operacionalizar este compartilhamento dentro das organizações vêm sendo realizadas em diversos campos do conhecimento. Inserindo-se nessas discussões, o objetivo central desta pesquisa foi analisar como o sentimento de que informação é poder interfere na percepção e na atitude dos funcionários de organizações, tendo como pano de fundo a concepção da metáfora da organização como arena política proposta por Morgan (2002). Para tal, realizouse um estudo descritivo dentro de uma instituição financeira por meio da aplicação de um questionário. Em função dos resultados obtidos, é possível inferir que a informação, ainda hoje, é utilizada de forma estratégica e entendida como "moeda de troca" para a ascensão na carreira e o reconhecimento pessoal. $\mathrm{O}$ artigo apresenta, também, algumas implicações desses resultados, sugerindo um olhar mais estratégico para a Gestão de Pessoas, principalmente no que diz respeito ao recrutamento, à seleção, ao reconhecimento (financeiro ou não) e às políticas de carreira.
\end{abstract}

Palavras-chave: Compartilhamento da informação. Arena política. Instituição financeira. Poder.

\section{Introdução}

Em meio a um cenário de muitas transformações, a informação se consolidou como um imprescindível recurso organizacional, ora para subsidiar os processos de tomada de decisão, ora para dar sustentação ao conhecimento que é construído e reconstruído dentro da proposta de gestão do conhecimento. Nesse cenário, o compartilhamento da informação tornou-se uma das bases para a busca cotidiana de um desempenho melhor dentro das organizações, acompanhando o crescimento exponencial da concorrência entre elas. 
O compartilhamento da informação, segundo Davenport (2000), realizase no ato voluntário das pessoas em partilhar, e, no que diz respeito às organizações, é o principal elemento das relações interorganizacionais (WANG et al., 2008). No entanto, o compartilhamento não é um ato natural, não ocorrendo facilmente em seu interior. Em pesquisas já realizadas, Ipê (2003), Alcará et al. (2009), Alves e Barbosa (2010), dentre outros, apontam que existem barreiras e aspectos que exercem influência no ato de compartilhamento da informação, sendo o poder, gerado pela informação, um exemplo de barreira apontado. Apoiando-se nesses achados de pesquisa, resolveu-se estudar as implicações que o poder possui frente ao ato do compartilhamento da informação. Nesta direção, o norte deste trabalho é a tentativa de analisar como o sentimento de que informação significa poder interfere na percepção e na atitude dos funcionários frente ao ato de partilha da informação.

O aporte teórico utilizado para a compreensão acerca do que é "poder" e quais são suas implicações no comportamento das pessoas dentro dos limites organizacionais, baseou-se no conceito elaborado por Morgan (2002), que compara uma organização como uma arena política. Este conceito aponta que, em âmbito organizacional, os participantes dessas organizações possuem interesses e objetivos próprios, os quais, muitas vezes, sobrepõem e/ou divergem dos objetivos organizacionais.

Adotou-se, como critério metodológico, a realização de uma pesquisa em uma instituição financeira, localizada na porção leste do estado de Minas Gerais. A pesquisa se classifica como um estudo descritivo, e como instrumento de coleta de dados optou-se pela aplicação de um questionário, favorecendo o processo de realização de análises quantitativas por meio do tratamento dos dados utilizando-se da planilha Excel®.

Os dados apontam que a informação ainda é percebida como um recurso que dá ao seu proprietário algum poder e, por isso, é utilizada de forma estratégica nos limites internos da arena política organizacional. $\mathrm{Na}$ instituição pesquisada, as análises indicam que a informação é buscada de forma individual - tanto no âmbito formal quanto informal - objetivando melhorias na carreira e 
no crescimento pessoal, apesar da organização estimular o compartilhamento, dentre outros meios, pelo desenvolvimento do trabalho em equipe.

O estudo é uma contribuição ao debate teórico que se formou em torno da temática do compartilhamento da informação dentro do contexto organizacional e, mais especificamente, no que diz respeito às barreiras ao ato da partilha das informações. Os resultados buscam contribuir para a adoção de políticas de recrutamento, seleção, treinamento e desenvolvimento, elementos de impacto na gestão de pessoas, dentro de uma visão mais estratégica que esteja alinhada com os objetivos que a organização deseja alcançar.

\section{Informação: do conceito à perspectiva de recurso organizacional}

O termo "informação" é um conceito multidimensionado e, por isso, encontra-se associado a diferentes terminologias em diversos contextos, e defronta-se com definições, muitas vezes, complementares e não necessariamente excludentes. Para o trabalho em referência, utilizou-se o conceito de informação dentro do paradigma social (CAPURRO, 2003), que concebe os processos informacionais para um usuário que é "um ser-no-mundo", e está impregnado de seu contexto cultural, consequentemente não agindo com passividade, como fora dimensionado no paradigma cognitivo.

Quando se trata de organizações, Tomaél (2012, p. 8) considera que as relações de trabalho são como um “[...] espaço privilegiado de compartilhamento da informação e do conhecimento, entre atores diversos: trabalhadores/produtores - organizadores da informação -, usuários e instituições". Sob a perspectiva teórica dessa autora, o fluxo das informações e o seu compartilhamento estão diretamente relacionados, sendo o fluxo parte constitutivo do ato de compartilhamento.

Desse modo, o compartilhamento encontra lugar especial dentro das organizações, sendo elemento crucial das relações interorganizacionais (WANG et al., 2008). Esse aspecto já havia sido apontado por Solomon (2002), quando considerou que a informação é construída na interação dos indivíduos com a tecnologia disponível e com as estruturas existentes na vida e no contexto de 
trabalho. Segundo Tomaél (2005), “O fluxo da informação acompanha o movimento humano" (p. 35).

Daí deriva o impasse de que esse processo não se consiga gerenciar, haja vista que informação e conhecimento são, essencialmente, criações humanas. Nunca se conseguirá administrá-los se não for considerado que as pessoas desempenham, nesse cenário, um papel fundamental (ALVES; BARBOSA, 2010) - papel esse que se justifica por ser voluntário, pois se inicia da vontade das pessoas. Barros (1994) destaca que tudo isso acontece pois compartilhar está relacionado com partilhar, o que se configura como um ato de decisão pessoal ou, melhor dizendo, precisa ter disponibilidade para realizá-lo.

Esse aspecto denota a necessidade de motivação e de vontade, o que enfatiza a participação essencial das pessoas. Desse modo, Davenport (2000, p. 114) alerta para o fato de que "[...] compartilhar seja algo mais fácil de dizer do que de fazer [...] por um bom motivo: em uma organização, quem controla a informação certa também possui poder".

São essas nuances que fazem com que o compartilhamento da informação seja um processo carregado de desafios. Alcará et al. (2009, p. 170) argumentam que o compartilhamento da informação “[...] é essencial para a construção de novos conhecimentos, porém esse processo pode ser influenciado por diferentes fatores." Os autores apontam que a organização deve criar um contexto de trabalho que favoreça o compartilhamento. Marchand, Kettinger e Rollins (2000) alertam para a necessidade de existirem pré-condições para que o ato de compartilhamento da informação possa acontecer. Essas pré-condições são: (1) a existência de uma linguagem e de significados que são partilhados em uma base comum pelas pessoas que formam a organização; (2) a existência de um relacionamento entre os membros da organização e o conhecimento interpessoal no contexto de trabalho dessas pessoas; (3) a confiabilidade entre as pessoas, para que o compartilhamento das informações aconteça em um nível de verdade em função da inexistência de interesses pessoais e/ou de terceiros; e (4) a existência de um objetivo associado a uma recompensa pelo ato de compartilhar. 
No entanto, em uma organização, diversos fatores coexistem dentro de limites estabelecidos pelo formato estrutural adotado. Estrutura hierárquica, poder, status e política de ascensão na carreira são, algumas vezes, entendidos como pontos de distinção de mérito e de promoções no cenário organizacional. Esses aspectos podem conduzir, algumas vezes, ao entendimento de que informação é poder, e poder pode significar muito dentro da arena política que a organização representa.

Em uma pesquisa realizada, Raban e Rafaeli (2007) encontraram, com base nos resultados, que a propriedade pessoal da informação possui papel importante na vontade de compartilhar. Sob essa perspectiva "O valor da informação está nos olhos de quem vê. A condição de proprietário afeta o valor da informação no compartilhamento e a propensão a partilhar pode ser afetada" (RABAN; RAFAELI, 2007, p. 2377, tradução nossa).

Ipê (2003) assevera que o compartilhamento da informação pode ser afetado por fatores diversos. Primeiramente, ela pondera sobre a natureza do conhecimento - tácito ou explícito - e na valorização do conhecimento que podem ser influenciadores do compartilhamento. Outro fator de influência é a motivação das pessoas para o compartilhamento que envolve aspectos internos e externos. Em relação aos fatores internos, está a variável de poder proveniente de um sentimento de que "conhecimento é poder", o que pode, em grande parte das vezes, dificultar o compartilhamento (IPÊ, 2003). Outro fator interno é a reciprocidade, que, segundo a autora, é o sentimento de obter algo em troca ao se realizar o compartilhamento. Ou seja, a reciprocidade é uma resultante do compartilhamento. Quanto aos fatores externos, está o relacionamento - que se tem com o outro - e a recompensa por partilhar.

Continuando sua análise, Ipê (2003) aponta ainda a oportunidade para o compartilhamento, que inclui oportunidades formais e informais. As formais dizem respeito àqueles meios que a organização oferece, por exemplo: programas de treinamento, equipes de trabalho e sistemas formais de informação. Em relação aos informais, têm-se os canais de relacionamento (que podem favorecer, segundo a autora, amizade e confiança) e de aprendizagem. Por último, Ipê (2003) relaciona a cultura do ambiente de trabalho como fator 
capaz de influenciar o compartilhamento. A cultura está relacionada com o arcabouço de estratégicas políticas e comportamentos ligados à partilha da informação. Davenport (2000) chama esse aspecto de "ambiente informacional", sendo o qual cria o cenário por onde toda a informação circulará.

Na mesma linha de raciocínio, Alves e Barbosa (2010) apontam fatores individuais e fatores organizacionais que influenciam o compartilhamento da informação. Muitos desses fatores têm a mesma base teórica utilizada por Ipê (2003), o que acarreta uma coincidência nas análises. Como fatores individuais, os autores relacionam motivação, confiança, reciprocidade e sentimento de pertencimento. Dentre os fatores organizacionais, os autores citam a cultura organizacional, natureza do conhecimento, mecanismo de compartilhamento, prestígio (poder e status) e premiações.

A motivação é compreendida por Alves e Barbosa (2010) na mesma perspectiva teórica de Ipê (2003), apontando que o impulso para compartilhar vem da percepção do que é importante, ou seja, pelo poder que o conhecimento partilhado pode propiciar, pela relação recíproca de troca que pode ser desenvolvida, pelas recompensas e pelas oportunidades que a organização oferece aos participantes do ato de compartilhar.

Como fator individual ressaltado por Alves e Barbosa (2010), tem-se a confiança, que é entendida como elemento primordial no processo de compartilhamento, pois é a base para o desenvolvimento dos relacionamentos interpessoais. Barney e Hansen (1994, p. 176) argumentam que "[...] a confiança é o sentimento mútuo de que nenhuma das partes envolvidas explorará as vulnerabilidades da outra". A reciprocidade também é apontada como um fator individual que interfere no ato do compartilhamento da informação. Cohen (1998) aponta que compartilhar está diretamente relacionado ao sentimento de reciprocidade, haja vista que as pessoas só realizam a partilha de suas informações se receberem algo em troca.

O sentimento de pertencimento é outro fator individual que promove, segundo Cohen (1998), o fortalecimento dos níveis de confiança, da reciprocidade e o desenvolvimento de uma ação coletiva assentada no espírito de equipe. Esse aspecto encontra fundamento nas conclusões da Experiência de 
Hawthorne, desenvolvida por Elton Mayo em 1924. As conclusões tiradas a partir da experiência apontam que o homem é um ser social, e por isso necessita estar integrado (MAXIMIANO, 2000). A perspectiva do Homem Social, segundo Leite e Albuquerque (2009), reconhece que as organizações são agrupamentos sociais, e não tem uma base individual enfatizando, dessa forma, o esforço da equipe e a unidade grupal. Corroborando essa perspectiva, Borelli e Tomaél (2012, p. 74) afirmam que "[...] as pessoas se sentem mais propensas a ajudar quando observam que compartilhar informação é importante, ideal e esperado pelo grupo", haja vista que a percepção de que o ato de compartilhar é benéfico e vantajoso impulsiona a vontade para tal processo.

Além desses aspectos individuais, têm-se também os fatores organizacionais, que ao mesmo tempo em que podem contribuir para o fluxo de compartilhamento, também podem exercer influência negativa a tal fluxo. $\mathrm{O}$ primeiro ponto realçado é a cultura organizacional, que envolve a criação e manutenção de um espírito de equipe que norteará o comportamento dos funcionários frente ao desenvolvimento dos processos de trabalho. Dessa forma, a cultura estabelecerá os valores, as crenças, as políticas e as diretrizes para a promoção de um ambiente corporativo voltado para o compartilhamento, o qual se configura na cultura informacional. Desse modo, de acordo com Alves (2011, p. 48), a “[...] cultura informacional é uma parte da cultura organizacional que influencia e contribui diretamente para a gestão e uso direcionados da informação".

Tal como Ipê (2003), Alves (2011) também reafirma a influência que a natureza do conhecimento exerce sobre o processo de compartilhamento. $\mathrm{O}$ conhecimento tácito, segundo a autora, é de difícil partilha, pois exige pensar em como e quando realizá-la (IPÊ, 2003). Já o conhecimento explícito, por já estar formalizado, é mais fácil de ser transmitido.

Outro fator organizacional que interfere no compartilhamento são os próprios mecanismos criados pela organização para facilitar a partilha da informação. Esses mecanismos podem ser formais e informais. Mecanismos formais consistem em sistemas gerenciais de informação e, os informais, incluem a comunicação interpessoal, reuniões espontâneas ou agendadas, 
observações diretas e relatórios também informais. Segundo Alves (2011, p. 49) “[...] alguns estudos revelam que grande parte de informações são compartilhadas informalmente, por meio dos canais de relacionamento e aprendizagem informais".

O terceiro fator de influência organizacional é o prestígio que, na leitura de Alves e Barbosa (2010), consiste em poder e status. De acordo com os autores, o poder deve ser compreendido como um sentimento que está diretamente vinculado à ideia de que conhecimento é poder. A posse da informação e do conhecimento propicia uma sensação de diferenciação e superioridade para aquele que os possui; sendo assim, o ato de compartilhar envolve um risco, qual seja a perda do poder. Cabrera e Cabrera (2002, p. 697) argumentam que "[...] o mais importante custo associado ao compartilhamento do conhecimento é a vulnerabilidade sentida por quem revela sua ideia em certos contextos organizacionais.”. Em vários cenários, a cultura existente valoriza o poder da informação, em que, muitas vezes, ser "guardião" da informação é o diferencial competitivo de cada pessoa dentro de uma hierarquia de cargos rígida. Alves e Barbosa (2010) apontam que a necessidade de ter prestígio pode impulsionar a busca por promoção individual em lugar dos objetivos coletivos. Vale ressaltar que "o prestígio como um fator influenciador do comportamento humano" pode "ter sua origem no perfil e personalidade de cada indivíduo" (ALVES, 2011, p. 52). Por outro lado, os autores acreditam que, vivendo em uma sociedade onde há uma sobrecarga de informação, o valor associado ao poder e ao status de propriedade esteja decaindo, e que o verdadeiro poder, atualmente, concentra-se na capacidade de construção de novos conhecimentos e da aprendizagem, que só acontece com um comportamento de partilha.

Por último, mas não menos importante, existe a capacidade das organizações em estimular a ação voluntária para o compartilhamento, fazendo uso de premiações (recompensas e incentivos) com o objetivo de ativar as trocas recíprocas de informações. Hall (2001) aponta três formas de premiações: (a) premiações por meio de incentivos financeiros, (b) progressão na carreira, e (c) 
a construção de boa reputação por meio do reconhecimento dos pares que também é uma estratégia de recompensa.

Com o relato dos fatores que influenciam o compartilhamento da informação, é possível observar que cada um deles constituiu uma faceta do comportamento das pessoas que integram o espaço organizacional. Para esse estudo, o escopo de discussão recai sobre o fator poder que, combinado com as nuances do ambiente organizacional dentro da perspectiva de arena política, torna-se fator essencial na vontade de compartilhar informação.

\section{A Organização como arena política e o compartilhamento da informação}

Dizer que a sociedade moderna é uma sociedade de organizações é pisar em lugar comum, assim como reforçar a sua importância dentro dessa sociedade também o é. Krausz (1991, p. 33-34) assevera que uma organização é criada com o objetivo de produzir resultados, e assim “[...] há necessidade de se padronizar comportamentos, direcionar a ação conjunta dos indivíduos e controlá-la para que não se desvie dos objetivos estabelecidos".

Desse modo, compreendem-se as organizações como um sistema formalmente constituído por recursos (humanos, materiais, financeiros e informações) que são combinados, de forma deliberada, para alcançarem objetivos (BERTALANFFY, 1968). Esse teor de racionalidade é típico de organizações, lugares de racionalidade extrema, onde os recursos são alocados de forma a propiciarem os melhores níveis de eficiência e de eficácia fundamentados na lógica cartesiana da gestão.

Entretanto, os pressupostos teóricos trazidos pela Teoria Estruturalista formatam uma concepção diferenciada sobre organizações. Na leitura de Etzioni (1974, p. 68), “[...] os estruturalistas veem a organização como uma unidade social grande e complexa, onde interagem muitos grupos sociais [...]”, e que em função disso, é permeada de conflitos.

Sob essa perspectiva teórica, Morgan (2002, p. 189) desenvolveu a Metáfora da Organização como Arena Política, que se contrapõe à noção de que as "[...] organizações são empresas racionais e integradas e possuem objetivos 
comuns $[\ldots] "$. Essa metáfora, segundo o autor, "[...] encoraja-nos a ver as organizações como redes soltas de pessoas com interesses divergentes que se juntam por motivo de convivência pessoal (ganhar a vida, desenvolver uma carreira, defender uma meta ou objetivo pessoal).” (MORGAN, 2002, 186).

A partir daí, a política, segundo o autor " [...] vem da diversidade de interesses o que dá origem aos 'arranjos', negociações e outros processos de formação de coalizões de influência mútua que tanto afetam a vida da organização" (MORGAN, 2002, p. 182-183). Para ele, a política se manifesta nos jogos de poder, nas intrigas interpessoais e nas artimanhas que são consequências do fluxo de atividades que são desenvolvidas no contexto organizacional. Partilhando dessa visão, Pereira, Santos e Brito (2006) apontam que a organização deve ser considerada como um espaço de estabelecimento e de negociação de princípios, o qual envolve processos de articulação de interesses entre diversos membros. No entanto, os autores lembram que "Cada ator organizacional pretende reforçar seus interesses e legitimar sua ação para garantir seu espaço e posição na estrutura organizacional.” (PEREIRA; SANTOS; BRITO, 2006, p. 5).

Segundo Morgan (2002, p. 185, grifo do autor), tudo isto acontece porque quando passam a integrar organizações, as pessoas “[...] trazem interesses pessoais, suas personalidades, atitudes pessoais, valores, preferências, crenças e compromissos fora do trabalho que determinam a maneira como agem em relação ao trabalho e à carreira.”. São esses interesses pessoais que direcionam as “[...] predisposições que englobam metas, valores, desejos, expectativas e outras orientações e inclinações que levam uma pessoa a agir de uma maneira ou de outra" (MORGAN, 2002, p. 185). Desse modo, segundo o autor, a política organizacional acontece de uma forma invisível, sendo perceptível somente aos que estão envolvidos.

Assim, as atitudes de cada pessoa no ambiente organizacional estão arraigadas em seus interesses, o que a leva a desenvolver relacionamentos diferentes com as atividades do trabalho e também estilos, que segundo Morgan (2002, p. 186), podem ser sintetizados em “[...] carreirismo, jogo, dedicação ao 
trabalho, rigidez, 'proteção do território', zelo, desapego e despreocupação que dão a vida política organizacional seu caráter especial".

Desse modo, o espaço organizacional se transforma em uma arena política, onde cada indivíduo, para realizar e atender aos seus interesses, utiliza de todos os recursos disponíveis. Como os recursos são limitados, a competição se instala, produzindo coalizões e um comportamento político que passa a balizar todas as ações e decisões a serem realizadas na vida cotidiana das organizações.

São nesses arranjos políticos que surge o poder. De acordo com Crozier e Friedberg (1981, p. 33), as pessoas dentro das organizações não podem atingir seus objetivos senão por meio do "[...] exercício de relação de poder, mas ao mesmo tempo não podem dispor de poder uns sobre os outros, a não ser pela procura de objetivos coletivos.". Segundo esses autores, o poder é um elemento indissolúvel das organizações, e muitas vezes é alimentado pela estrutura hierárquica e pelos processos formais adotados. Elias (1994, p. 53) argumenta que o poder mantém relação com o fato de existirem indivíduos - ou grupos que podem “[...] reter ou monopolizar algo que outros necessitam [...] assim, quanto maiores forem as necessidades destas últimas, maior é o poder que detêm os primeiros".

Krausz (1991, p. 11), já havia apontado que o poder “[...] é onipresente na vida social [...]" e deve ser compreendido como um "[...] fenômeno subjetivo, com repercussões a nível intrapessoal, interpessoal, grupal e social, pois seus efeitos se dão nas relações entre indivíduos" (KRAUSZ, 1991, p. 14). Por isso “[...] o comportamento dos participantes não é apenas baseado numa racionalidade instrumental econômica, mas também, a partir de uma racionalidade política e manobras" (FRIEDBERG, 1995, p. 119).

A partir de então, nessa Arena tem-se vários políticos organizacionais que controlam fluxos de informação e de conhecimento, partilhando com diferentes pessoas de forma diferenciada e com conteúdos diferenciados, de maneira a favorecer os seus interesses (MORGAN, 2002). Assim, a informação como recurso escasso e de propriedade muitas vezes individual torna-se objeto de negociação entre os participantes da organização (HARDY; CLEGG, 2001). 
Esses movimentos fazem com que a informação seja tratada de forma assimétrica no contexto organizacional, sendo assim, transformada em um instrumento de poder.

Segundo Araujo (2006, p. 332) “[...] esse jogo é oriundo do fato de que algumas pessoas detêm mais informação do que outros”. Criam-se assim os "guardiões da informação" ou "filtros de informação", que decidem para quem a informação deve ir. Esses filtros, na análise de Morgan (2002, p. 199), “[...] abrem e fecham os canais de comunicação e filtram, resumem, analisam e formulam o conhecimento de acordo com uma visão do mundo que favorece seus interesses", fazendo com que a informação se torne um segredo de alguns. Macedo e Barbosa (2000, p. 87), fazendo referência ao segredo, associam-no ao poder, e lembram que "Entre os povos primitivos, o poder estava nas mãos dos bruxos, que detinham o conhecimento das ervas e os processos de cura das doenças".

Ampliando essa análise, Cabrera e Cabrera (2002) apontam para além do poder, e sugerem que existe um custo relacionado ao compartilhamento do conhecimento, que é a vulnerabilidade. Em certos contextos organizacionais, quem compartilha se expõe e, algumas vezes, dá ao seu colega de trabalho a possibilidade de deteriorar sua capacidade (a do primeiro) e sobressair-se dentro dessa organização.

Porém, é preciso lembrar da evolução da sociedade, que nesse momento de conexões intensivas tanto intra quanto interorganizacionais, tem no conhecimento organizacional o fator essencial da competitividade. Paralelo a isso, as organizações necessitam mudar e compreender que "[...] compartilhar, nesse caso, alimenta todos os atores que participam desse processo, todos saem com maior nível de informação e de conhecimento." (TOMAÉL, 2012, p. 7). Desse modo, poder e política necessitam estar alinhados, objetivando contribuir para um maior desenvolvimento organizacional. 


\section{Procedimentos metodológicos}

Partindo-se do questionamento inicial e buscando também alargar os limites do estado da arte sobre o respectivo tema, estabeleceu-se como tipo de pesquisa a descritiva. De acordo com Malhotra (2006), as pesquisas descritivas possuem um caráter conclusivo e objetivo bem demarcado, e sua tônica é apresentar soluções para as inquietações delineadas.

Como unidade de análise, optou-se por uma instituição financeira localizada na Zona da Mata Mineira. A instituição financeira possui 24 anos e possui, atualmente, 215 colaboradores distribuídos em 17 Postos de Atendimento Cooperativo. A escolha dessa instituição se deu, dentre outros aspectos, em decorrência de seu desenvolvimento, uma vez que atualmente está ocupando o segundo lugar no Estado de Minas Gerais como a maior cooperativa de Crédito e o primeiro lugar em captação de caderneta de poupança no Estado, de acordo com dados institucionais. Dentre os Postos de Atendimento da instituição, para a realização deste estudo escolheu-se o Central e o Centro Administrativo, o que resultou em uma população de 79 colaboradores. Vale ressaltar que não houve a intenção de se estratificar a amostra por cargos, tempo de organização e faixa etária dos respondentes. Isso ocorreu de forma aleatória, pois quando se entregou os questionários, foi colocada a liberdade de participar ou não, ou seja, deixou-se à vontade do colaborador a participação ou não no estudo.

Em relação à amostra, optou-se utilizar uma que fosse estatisticamente estabelecida. No Quadro 1, apresenta-se o número dos elementos da amostra encontrada e a quantidade de elementos da população obtida durante a pesquisa. A justificativa para o número superior de elementos pesquisados foi a tentativa de se minimizar a probabilidade de que ocorresse um viés que comprometesse a análise, ou que a taxa de retorno dos questionários inviabilizasse o estudo. 
Quadro 1 - Elementos da amostra

\begin{tabular}{|l|c|}
\hline Item & Elementos \\
\hline Amostra sugerida pelo método estatístico & 19 \\
\hline Amostra obtida na pesquisa & 27 \\
\hline
\end{tabular}

Fonte: Dados da pesquisa.

Para a coleta de dados, utilizou-se de um questionário, o qual, na percepção de Gil (1999, p. 128), é uma “[...] técnica de investigação [...], tendo por objetivo o conhecimento de opiniões, crenças, sentimento, interesses, expectativas, situações vivenciadas etc".

Os dados coletados foram tabulados e processados na planilha eletrônica do Excel, e a partir dos resultados obtidos, traçaram-se análises a respeito do tema objeto desse estudo.

\section{Resultados e discussões}

A amostra pesquisada tem o seguinte perfil: os respondentes possuem entre $18 \mathrm{e}$ $24 \operatorname{anos}$ (10 respondentes), são do nível operacional (14 respondentes) - ou seja, trabalham no Posto de Atendimento Cooperado (agência) -, e possuem mais de um ano de empresa, chegando ao máximo de cinco anos (20 respondentes). Em suma, os dados demonstram que a maior parte dos respondentes é jovem e possui pouco tempo de organização. Os gráficos 1, 2 e 3 demonstram essas análises. 
Gráfico 1 - Faixa Etária

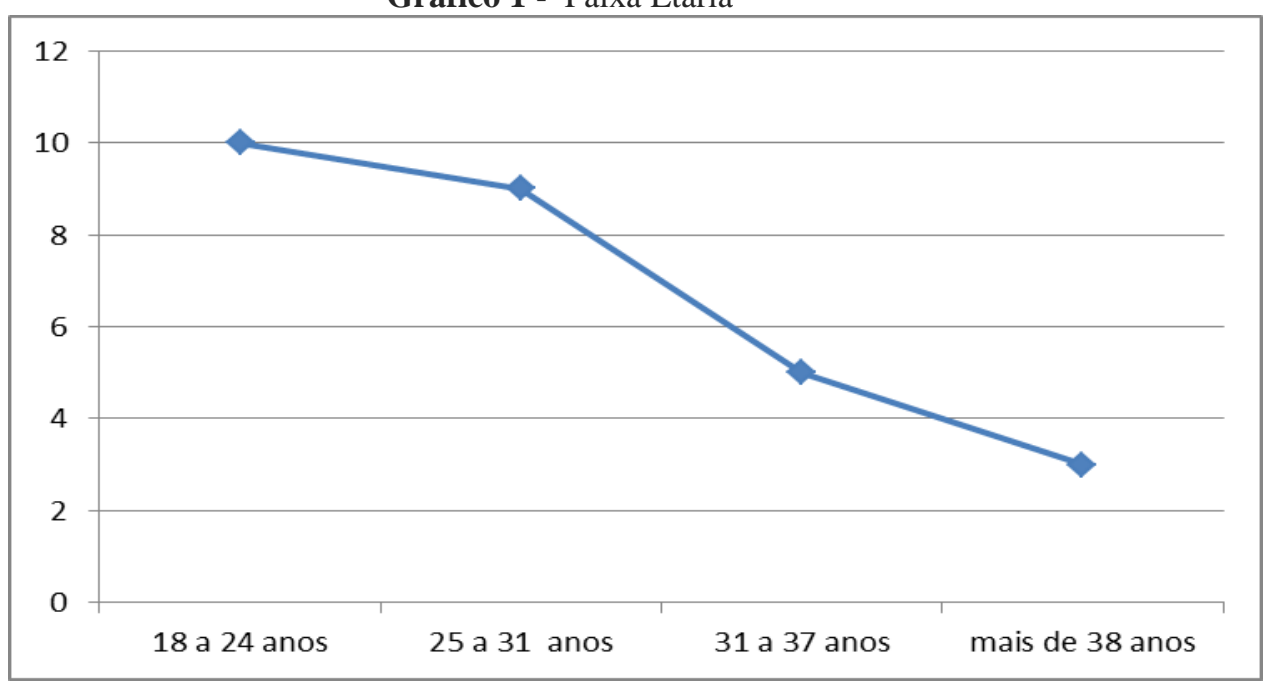

Fonte: Dados da pesquisa.

Em relação ao tema central deste estudo, a informação e o poder, tem-se que, mediante as respostas colhidas, 67\% dos respondentes apontam que informação é poder, enquanto que $18 \%$ da amostra pesquisada aponta que informação é poder, mas possui algumas exceções. Esses percentuais representam 23 pessoas dentro de um universo amostral de 27 , o que reforça a perspectiva de que em um ambiente organizacional, a informação ainda é vista como um recurso escasso e que tem características importantes, chegando a ser considerado poder - isto é, um diferencial em meio às variáveis componentes desse ambiente.

Estas análises reforçam o que é apontado por Morgan (2002), ao explicar que as pessoas que compõem as diferentes organizações possuem interesses e objetivos próprios, os quais, muitas vezes, sobrepõem e/ou divergem dos objetivos organizacionais. Por isto, a informação se torna um recurso organizacional estratégico que pode ser utilizada dependendo dos interesses pessoais de cada um. 
Gráfico 2 - Cargo ocupado

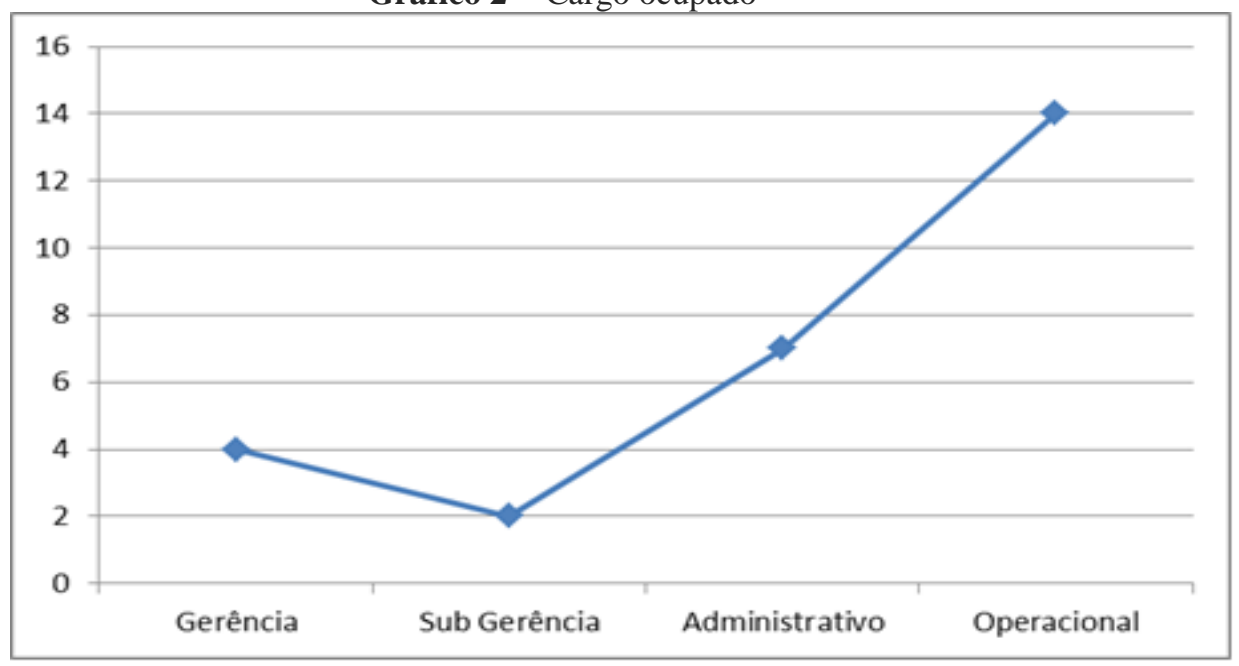

Fonte: Dados da Pesquisa.

Gráfico 3 - Tempo de organização

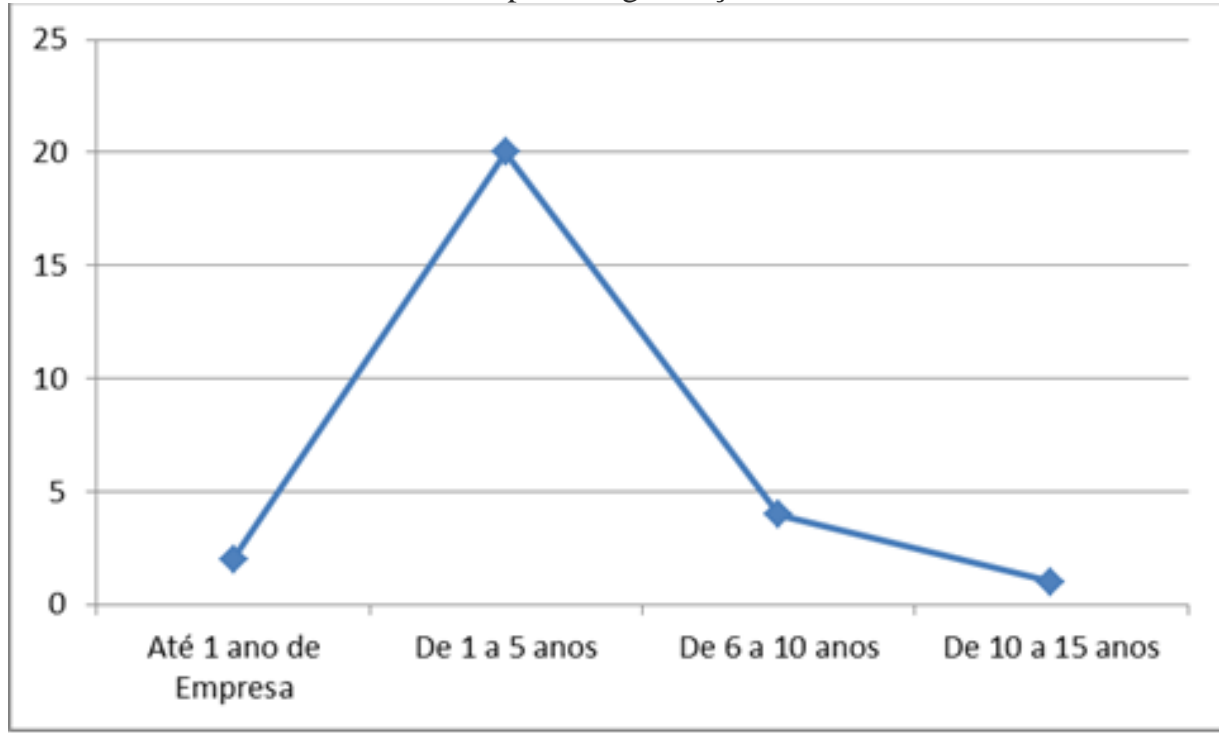

Fonte: Dados da Pesquisa

Desse percentual de 67\%, três são gerentes, um é subgerente, seis são do nível administrativo e oito são do nível operacional. Em relação à resposta "sim; mas, com algumas exceções", tiveram-se $18 \%$ da amostra, isto é, cinco respondentes distribuídos de modo que: um é gerente, um é responsável pelo setor (subgerente), um é do setor administrativo e dois são do setor operacional. Levando-se em consideração as respostas dos cargos de gerente e de subgerentes, percebem-se concepções que contradizem o comportamento 
esperado por eles no papel que possuem dentro da organização. Se possuem cargos mais elevados na estrutura hierárquica, parte-se do princípio que seria necessário que estivessem mais alinhados com os objetivos organizacionais, ao invés de terem um comportamento individualista e político frente ao ato de compartilhamento. Outro aspecto a ser considerado é que gerentes transmitem objetivos organizacionais e estabelecem estratégias a serem desenvolvidas. A percepção de que informação é poder, mesmo em alguns casos, pode direcionar o comportamento de seus colaboradores (do nível administrativo e do nível operacional) fazendo-os tratar a informação, como apontado anteriormente, como fator estratégico para atingir objetivos que estejam associados aos interesses individuais. Outra consideração a ser feita é a percepção de que informação é uma forma de poder como totalidade entre os respondentes do setor administrativo, reforçando o comportamento já existente dos gerentes e subgerentes de terem a informação como trunfo que será utilizado ou não dependendo da situação e das pessoas envolvidas. Vale ressaltar que, na amostra pesquisada, a faixa etária e o tempo de organização não influenciaram essa percepção, o que vai ao encontro da análise feita por Alves (2011, p. 52), quando aponta que o poder e o status é um fator influenciador do comportamento humano "podendo ter sua origem no perfil e personalidade de cada indivíduo". Decorrente dessa percepção, 56\% da amostra (15 pessoas) apontam que as informações devem ser guardadas e utilizadas de forma estratégica, enquanto $23 \%$ dos respondentes (6 pessoas) apontam a utilização estratégica da informação é algo relativo. Essa análise reforça a perspectiva acima, pois percebendo que a informação é poder, a atitude esperada é justamente essa. Esse aspecto reforça a análise de Morgan (2002), que aponta que as organizações são sistemas políticos impregnados de interesses diversos, conflitos e poder que são utilizados para realizar coalizões, jogos e ações politicamente articuladas em benefício próprio ou de um grupo. Esses dados são reforçados pelos totais obtidos quando os respondentes apontam que se preocupam em coletar informações (tanto dentro quanto fora do contexto organizacional) que sejam de interesse da organização e que lhes propiciem 
possibilidades de ajudar no desempenhar de suas tarefas e, consequentemente, no desenvolvimento de suas carreiras.

No entanto, a maioria das pessoas que participou do estudo (24 pessoas $87 \%$ da amostra) afirma que o ato de compartilhar faz com que a pessoa se sinta útil, e a mesma proporção de pessoas afirma também que o ato de compartilhar faz com que se criem novas possibilidades de relacionamentos, ao passo que $81 \%$ (22 pessoas) dos respondentes apontam ainda que é importante confiar nas informações que recebem. Reforçando esse aspecto, todos, sem exceção, apontam que na organização em que trabalham são compartilhadas informações confiáveis. Além disso, também apontam que a organização cria e estimula a partilha de informações, criando meios digitais (Intranet) e utilizando-se de reuniões, treinamentos e encontros informais que objetivam desenvolverem relacionamentos que possibilitem o vínculo entre os colaboradores. Este aspecto vai ao encontro do apontado por Ipê (2003) e Davenport (2000) quando afirmam que as organizações devem criar um ambiente que favoreça o compartilhamento da informação e, conjuntamente, estratégias que estimulem um comportamento de partilha. E, também, que fortaleçam os vínculos entre os funcionários, haja vista que a informação é construída na interação das pessoas (SOLOMON, 2002).

No entanto, é interessante apontar que individualmente, os dados apontam que o sentimento que conduz o comportamento geral dos respondentes é o de que compartilhar é desejoso - pela organização -, mas, no entanto, a atitude dos colaboradores de fato é a de não compartilhar todas as informações e tampouco compartilhar com todos. Esses dados são semelhantes aos resultados encontrados por Raban e Rafaeli (2007), quando esses apontam que a propriedade pessoal da informação possui papel importante na vontade de compartilhar. Desse modo "O valor da informação está nos olhos de quem vê. A condição de proprietário afeta o valor da informação no compartilhamento e a propensão a partilhar pode ser afetada [...]" (RABAN; RAFAELI, 2007, p. 2380, tradução nossa).

Separando-se os dados coletados por cargos ocupados, essa situação se reforça e desdobra-se em outros pontos mais reveladores. Da amostra 
pesquisada, quatro ocupam o cargo de gerentes. Todos os gerentes apontam que possuem um ótimo relacionamento com os seus colegas de trabalho e dois desses gerentes afirmam serem amigos desses colegas fora do ambiente de trabalho e, por isso, conversam com essas pessoas fora do cotidiano da organização sobre o trabalho e a organização em momentos informais. Os outros dois respondentes apontam que convivem com seus colegas de trabalho, mas que não possuem uma "amizade" e não conversam sobre o trabalho e sobre a organização em momentos informais. Todos, de uma forma geral, apontam que prestam muita atenção em informações que possam auxiliá-los em seu trabalho e em informações que possam melhorar a sua carreira. Apesar de agirem assim, os gerentes criticam a dificuldade de se obter informações no ambiente de trabalho, mas não têm atitudes que favoreçam o compartilhamento. Eles mesmos são "guardiões de informações" (MORGAN, 2002) agindo como "filtros de informação" que decidem para quem a informação poderá ser direcionada. Essa análise é reforçada quando dois dos gerentes apontam que "As informações devem ser utilizadas em momentos certos, e por isto deve-se guardá-las [...]" (sic). Reconhecem que a cultura da organização visa estimular o compartilhamento e que a partilha da informação é necessária e objetiva melhorar o nível de conhecimento, por isto a organização é adepta do trabalho em equipe.

Quanto aos subgerentes, duas pessoas desse cargo compõem a amostra, suas respostas não diferem muito das apresentadas pelos gerentes. Enquanto um deles concorda totalmente que a organização incentiva à formação de equipe, promove momentos que favorece o compartilhamento da informação e dá liberdade para que os seus colaboradores solicitem informações de quaisquer setores e, ainda, "escuta" as sugestões dadas, o outro discorda totalmente com todos esses itens. O interessante é que esse subgerente apresenta respostas mais críticas à organização, apesar de possuir pouco tempo de "casa" (está na faixa de um a cinco anos). Esse fato é estranho porque normalmente pessoas com pouco tempo de "casa" tendem a apresentar um comportamento mais motivado, já que parte-se do princípio que há uma ânsia por se desenvolver na carreira. Em relação ao compartilhamento da informação, os dois discordam que possuem o 
hábito de conversar com os seus amigos de trabalho sobre suas atividades e sobre a empresa. Porém, apresentam o mesmo comportamento dos gerentes quando esses afirmam que fora do ambiente de trabalho eles prestam atenção e buscam informações que possam lhes ajudar em sua tarefa, que podem fazer a empresa crescer e informações, ainda, que possam auxiliar na melhoria de suas carreiras. Os dois respondentes são enfáticos ao responderem que concordam totalmente que a pessoa somente deve trocar informações com aquelas que lhes repassam algo. Este ato confirma a reflexão de Cohen (1998) que argumenta que compartilhar está diretamente relacionado ao sentimento de reciprocidade, haja vista que as pessoas só realizam a partilha de suas informações se receberem algo em troca. Quando se busca saber a percepção deles em relação ao seu contexto de trabalho, os dois concordam que a organização cria ambientes que favorecem o compartilhamento - contudo, um dos respondentes afirma que discorda totalmente que na organização todas as pessoas sejam solidárias e que os colegas de trabalho se apoiem, principalmente no que diz respeito à partilha da informação. Vale ressaltar que os dois respondentes concordam totalmente que a organização se esforça para incentivar o trabalho em equipe.

No setor administrativo, encontra-se $26 \%$ da amostra ( 7 pessoas), e as suas respostas não se diferenciam muito das demais encontradas. A maioria dos respondentes não consegue avaliar o contexto organizacional no que diz respeito ao ambiente para o compartilhamento da informação. A maioria deles concorda totalmente que possui um ótimo relacionamento com seus colegas, mas que não conversam sobre o trabalho quando estão fora da organização. Somente três dos respondentes concordam totalmente que, tanto em ambientes formais quanto em ambientes informais, conversam sobre o trabalho e partilham informações com os seus amigos. Esse aspecto nos remete à análise feita por Cohen (1998) e Alves e Barbosa (2010), uma vez que afirmam que a confiança é a base para os relacionamentos que vão fundamentar e facilitar a partilha da informação. Esse aspecto se confirma no fato de seis respondentes afirmarem que concordam totalmente com a ideia de que informação é poder; porém, cinco desses concordam totalmente que depende de com quem se compartilha, o que nos remete a apontar que esses somente compartilham com quem há um nível de 
confiança e reciprocidade. Essas análises também se confirmam nas questões de que a informação - apesar de significar poder - deve ser compartilhada em momentos certos. Somente um dos respondentes concorda totalmente que a informação deve ser utilizada de forma estratégica e, por isso, existem momentos certos para partilhar ou não. De uma forma geral, apesar de haver exceções, os respondentes do setor administrativo estão mais propensos a compartilhar, mesmo que seja em um grupo e não no sentido completo do termo partilhar.

No setor operacional (nas agências de atendimento), tem-se 14 pessoas que integram a amostra, constituindo-se no maior número de participantes (52\%). De uma forma geral, a maioria dos respondentes (13 pessoas) concorda totalmente que a organização incentiva o trabalho em equipe e apontam que existe total liberdade para o compartilhamento da informação e para as sugestões, independente do cargo, o que faz com que a organização melhore os seus processos internos. Sete dos respondentes concordam totalmente que são amigos de seus colegas de trabalho, enquanto cinco discordam e dois não conseguem avaliar. Porém, estes não conversam com seus amigos - que pertencem à mesma empresa - sobre o trabalho em momentos informais. Três dos respondentes afirmam que depende muito da situação e das pessoas envolvidas para concordarem que a informação é poder, e por isso mesmo, compartilhar ou não depende da pessoa com quem se troca. Do total de 14, 11 dos respondentes apontam que a informação é sim poder no contexto organizacional, mas 10 respondentes, destes mesmos 14, discordam totalmente que somente se devem trocar informações quando for solicitado. Desses 10 respondentes, nove discordam totalmente que as informações devam ser utilizadas em momentos certos, e ainda afirmam que concordam totalmente que compartilhar faz com que as pessoas se sintam úteis. Vale lembrar que o setor operacional possui um comportamento mais voltado para o compartilhamento, apesar de alguns de seus elementos amostrais afirmarem que a informação é poder. 
A partir dessas análises, constata-se que a organização está empenhada em criar condições que favoreçam o compartilhamento no contexto de trabalho dentro da perspectiva apontada por Marchand, Kettinger e Rollins (2000).

Entretanto, os dados confirmam os aspectos apontados por Morgan (2002), na Metáfora da Organização como Arena Política, pois o sentimento de que informação é poder leva os participantes da organização a agirem de forma estratégica realizando coalizões, negociações e política, visando atender a interesses próprios, mais especificamente, a interesses relacionados à carreira e ao reconhecimento.

\section{Considerações finais}

O estudo procurou analisar como o sentimento de que informação é poder interfere na percepção e atitude dos funcionários frente ao ato de partilha da informação, tendo como unidade de análise uma instituição financeira.

A pesquisa analisou uma amostra de 27 elementos, que responderam de forma voluntária um questionário com perguntas que possibilitaram relacionar informação, poder e atitude em relação ao ato de partilhar. Com base nos dados obtidos, percebeu-se que a organização preocupa-se em criar um contexto que favoreça o compartilhamento, e busca incentivar o trabalho em equipe e o desenvolvimento de relacionamentos por meio de reuniões, meios digitais (Intranet), treinamento e confraternizações, procurando melhorar as relações interpessoais. Tudo isso pode levar ao aumento dos níveis de confiança, não que esse aspecto seja intencional; mas, segundo os respondentes, a organização estimula esse ambiente.

No que diz respeito ao objetivo central desta pesquisa, tem-se que os resultados encontrados demonstram que o sentimento de que informação é poder interfere na atitude para compartilhar. Decorrente disso, os respondentes a utilizam de forma estratégica objetivando atender a objetivos próprios. No contexto político da organização, a informação é ponto crucial, podendo alavancar carreiras e melhorar o status de quem a possui. De uma forma geral, é esse sentimento que subsidia o cotidiano de trabalho dessa organização. 
O sentimento de pertencimento e o envolvimento com a cultura organizacional precisam ser mais trabalhados, fazendo com que os participantes dessa organização melhorem os relacionamentos e criem laços de confiança mais amplos, procurando assim favorecer mais a atitude para partilhar.

É notório que a organização se preocupa com esse aspecto, na percepção da amostra pesquisada; porém, se faz necessário alterar comportamentos que hoje estão focados no indivíduo para atitudes voltadas para o grupo e para o todo organizacional. Pode ser que esses comportamentos sejam reflexos de uma educação para o trabalho, fundamentada nos preceitos da Escola Clássica da Administração, que compreendia que o fazer do trabalho é individual e não grupal. Faz-se mister que a organização compreenda que não só a cultura informacional precisa ser estimulada, mas também todo o contexto formal necessita ser repensado, procurando implantar uma estrutura organizacional que favoreça o trabalho em equipe e diminua o nível de política. Mais ainda, reconhecer que as pessoas precisam ser gerenciadas dentro da perspectiva de alinhamento estratégico, principalmente, no que diz respeito ao recrutamento, seleção, reconhecimento (financeiro ou não) e políticas de carreira. Esses podem ser caminhos a serem pensados para que o compartilhamento realmente aconteça dentro e fora de seus limites formais.

\section{Referências}

ALCARÁ, A. R. et al. Fatores que influenciam o compartilhamento da informação e do conhecimento. Perspectivas em Ciência da Informação, Belo Horizonte, v. 14, n. 1, p. 170-191, 2009. Disponível em: <http://www.scielo.br/pdf/pci/v14n1/v14n1a12>. Acesso em: 20 abr. 2014.

ALVES, A. Colaboração e compartilhamento da informação no ambiente organizacional. 2011. Dissertação (Mestrado em Ciência da Informação) Escola de Ciência da Informação da Universidade Federal de Minas Gerais, Belo Horizonte, Minas Gerais, 2011. Disponível em:

<http://www.bibliotecadigital.ufmg.br/dspace/bitstream/handle/1843/ECID$\underline{\text { 8LAKT7/dissertacao_alessandra alves_final_2011.pdf? sequence }=1>}$. Acesso em: 05 dez. 2015. 
ALVES, A.; BARBOSA, R. R. Influências e barreiras ao compartilhamento da informação: uma perspectiva teórica. Ciência da Informação, Brasília, v. 33, n. 2, p. 115-128, maio/ago. 2010.

ARAUJO, L. C. G. de. Gestão de pessoas: estratégias e integração organizacional. São Paulo: Atlas, 2006.

BARNEY, J.; HANSEN, M. A. Trustworthiness as a source of competitive advantage. Strategic Management Journal, [S.1.], v. 15, special issue, p. 175190, Winter 1994. Disponível em:

<http://ejournal.narotama.ac.id/files/TRUSTWORTHINESS\%20AS\%20A\%20S OURCE\% 200F\%20COMPETITIVE\%20ADVANTAGE.pdf>. Acesso em: 01 jun. 2015.

BARROS, L. A. Suporte a ambientes distribuídos para aprendizagem cooperativa. 1994. Tese (Doutorado em Ciências em Engenharia de Sistemas e Computação) - Programa de Pós-Graduação em Engenharia, Universidade Federal do Rio de Janeiro, Rio de Janeiro, 1994.

BERTALANFFY, L. V. General system theory. New York: George Braziller, 1968.

BORELLI, F.; TOMAÉL, M. I. Situações que envolvem o compartilhamento de informação por sistema informatizado. Em Questão, Porto Alegre, v. 18, n. 2 p. 71-83, jul./dez. 2012. Disponível em:

<http://seer.ufrgs.br/index.php/EmQuestao/article/view/21850/24055>. Acesso em: 11 mar. 2014.

CABRERA, A.; CABRERA, E. F. Knowledge-sharing dilemmas. Organization studies, Thousand Oaks, v. 23, n. 5, p. 687-710, 2002. Disponível em:

<http://oss.sagepub.com/content/23/5/687.abstract>. Acesso em: 2 abr. 2014.

CAPURRO, R. Epistemologia e ciência da informação. In: ENCONTRO NACIONAL DE PESQUISA EM CIÊNCIA DA INFORMAÇÃO, 5., Belo Horizonte, 2003. Anais... Belo Horizonte: UFMG, 2003. Disponível em: <www.capurro.de/enancib_p.htm>. Acesso em: 5 jul. 2010.

COHEN, D. Towards a knowledge context: report on the first annual U.C. Berkeley Forum on Knowledge and the firm. California Management Review, Berkeley, v. 40, n. 3, p. 22-39, 1998. Disponível em:

<http://cmr.ucpress.edu/content/4/3/22. full-text.pdf+html>. Acesso em: 1 un. 2015.

CROZIER,M.; FRIEDBERG,E. L'acteur et le système. [S.1.] : Seuil, 1981. Disponível em:

<http://mip-ms.cnam.fr/servlet/com.univ.collaboratif.utils. LectureFichiergw?

ID_FICHIER $=1295877017933$ > . Acesso em: 1 jun. 2015. 
DAVENPORT, T. H. Ecologia da informação: por que só a tecnologia não basta para o sucesso na era da informação. São Paulo: Futura, 2000.

ELIAS, N. Conocimiento y poder. Madrid: La Piqueta, 1994.

ETZIONI, A. Organizações modernas. 4 ed. São Paulo: Pioneira, 1974.

FRIEDBERG, E. O poder e a regra: dinâmica da ação organizada. Lisboa: Instituto Piaget, 1995.

GIL, A. C. Métodos e técnicas de pesquisa social. São Paulo: Atlas, 1999.

HALL, H. Input-friendliness: motivating knowledge sharing across intranets. Journal of Information Science, [S.1.], v. 27, n. 3, p. 139-146, 2001.

Disponível em: <http://jis.sagepub.com/cgi/reprint/27/3/139>. Acesso em: 05 Jan. 2015.

HARDY, C.; CLEGG, S. Alguns ousam chamá-lo de poder. In: CLEGG, S. R.; HARDY, C.; NORD, W. R. (Orgs.). Handbook de estudos organizacionais: reflexões e novas direções. São Paulo: Atlas, 2001. p. 260-289.

IPÊ, M. Knowledge sharing in organizations: a conceptual framework. Human Resource Development Review, [S.1.], v. 2, n. 4, p. 337-359, 2003. Disponível em: 〈http://hrd.sagepub.com/content/2/4/337.short>. Acesso em: 20 mar. 2014.

KRAUSZ, R. Compartilhando o poder nas organizações. São Paulo: Nobel, 1991.

LEITE, N. P.; ALBUQUERQUE, L. G. Gestão estratégica de pessoas: conceito, evolução e visão. In: LEITE, N. P.; ALBUQUERQUE, L. G. (Org.). Gestão de pessoas: perspectivas estratégicas. São Paulo: Atlas, 2009. p. 3-16.

MACEDO, M. F. G.; BARBOSA, A. L. F. Patentes, pesquisa e desenvolvimento: um manual de propriedade intelectual. Rio de Janeiro: Fiocruz, 2000. Disponível em: <http://books.scielo.org/id/6tmww/06>. Acesso em: 1 jun. 2015.

MALHOTRA, N. K. Pesquisa de marketing: uma orientação aplicada. 4 ed. Porto Alegre: Bookman, 2006.

MARCHAND, D. A.; KETTINGER, W. J.; ROLLINS, J. D. Desempenho empresarial e gestão da informação: a visão do topo. In: DAVENPORT, T. H.; MARCHAND, D. A.; DICKSON, T. Dominando a gestão da informação. Porto Alegre: Bookman, 2000. p. 21-27.

MAXIMIANO, A. C. A. Introdução à administração. 5. ed. rev. e ampl. São Paulo: Atlas, 2000. 
MORGAN, G. Imagens da organização. 2. ed. São Paulo: Atlas, 2002.

PEREIRA, M. C.; SANTOS, A. C.; BRITO, M. J. Tecnologia da informação, cultura e poder na Polícia Militar: uma análise interpretativa. Cadernos EBAPE.BR, Rio de Janeiro, v. 4, n. 1, p. 1-18, mar. 2006. Disponível em: <http://www.scielo.br/pdf/cebape/v4n1/v4n1a10.pdf>. Acesso em: 1 jun. 2015.

RABAN, D. R.; RAFAELI, S. Investigating ownership and the willingness to share information online. Computers in Human Behavior, [S.1.], n. 23, p. 2367-2382, 2007.

SOLOMON, P. Discovering information in contexto. Annual Review of information science and techmology, Medford, v. 36, p. 229-264, 2002. Disponível em:

<http://www.researchgate.net/publication/220141936_Discovering_information in_context>. Acesso em: 25 maio 2015.

TOMAÉL, M. I. Redes de conhecimento: o compartilhamento da informação e do conhecimento em consórcio de exportação do setor moveleiro. 2005. Tese (Doutorado em Ciência da Informação) - Escola de Ciência da Informação da Universidade Federal de Minas Gerais, Belo Horizonte, Minas Gerais, 2005. Disponível em:

$<$ http://www.bibliotecadigital.ufmg.br/dspace/bitstream/handle/1843/EARM6ZFQFX/doutorado__maria_in_s_toma_l.pdf? sequence $=1>$. Acesso em: 05 dez. 2015.

TOMAÉL, M. I. Compartilhamento da informação. Londrina: Eduel, 2012.

WANG, C. et al. Why focal firms share information? a study of the effects of power and information technology competence. In: PACIFIC ASIAN CONFERENCE ON INFORMATION SYSTEMS, 2008, Suzhou.

Proceedings... Suzhou: AIS, 2008. Disponível em: <http://www.pacisnet.org/file/2008/PACIS2008 Camera-Ready_Paper 068.pdf>. Acesso em: 25 maio2015.

\title{
Information sharing \& Power: relations and implications in the political organizational arena
}

\begin{abstract}
Discussions about the importance of information sharing and actions to operationalize it within organizations has been carried out in various fields of knowledge. Inserting these discussions, the central search scope was to analyze the feeling that information is power interfering in perception and attitude of employees, having as a backdrop the metaphor concept of the organization as a politic arena as proposed by Morgan (2002). Therefore, there was a descriptive
\end{abstract}


study in a financial institution by using the application of a questionnaire. As for the results obtained it can be inferred that information, even today, is used strategically and understood as " bargaining chips " for career advancement and personal recognition. This paper also presents some implications of these results and suggests a more strategic view of Human Resources Management, specially on recruitment, recognition (financial or not) and on career policies.

Keywords: Information sharing. Arena policy. Financial institution. Power.

Recebido: 24/01/2016

Aceito: 19/04/2016 